\title{
Family Physician Involvement in Cancer Care Follow-up: The Experience of a Cohort of Patients With Lung Cancer
}

\author{
Michèle Aubin, MD, PbD, CCFP, \\ FCFP $^{1,2,3,4}$ \\ Lucie Vézina, $M A^{4}$ \\ René Verreault, MD, PbD, FCFP, \\ $\mathrm{CCFP}^{1,5}$ \\ Lise Fillion, $\mathrm{PbD}^{3,6}$ \\ Éveline Hudon, MD, MSc, CCFP, \\ FCFP
}

François Lebmann, MD, CCFP, FCFP ${ }^{7}$

Yvan Leduc, MD, PbD, CCFP, FCFP ${ }^{2}$

Rénald Bergeron, MD, CCFP, FCFP $P^{2,4}$

Daniel Reinbarz, $M D, P b D^{5}$

Diane Morin, $\mathrm{PbD}^{6}$

'Research Unit of the Quebec Center of Excellence on Aging, Quebec, QC, Canada

${ }^{2}$ Department of Family Medicine and Emergency Medicine, Université Laval, Quebec, QC, Canada

${ }^{3}$ Maison Michel-Sarrazin Research Team in Palliative Care, Quebec, QC, Canada

${ }^{4}$ Laval Family Medicine Unit, Université Laval, Quebec, QC, Canada

${ }^{5}$ Department of Social and Preventive Medicine, Université Laval, Quebec, QC, Canada

${ }^{6}$ Faculty of Nursing, Université Laval, Quebec, QC, Canada

${ }^{7}$ Department of Family Medicine, Université de Montréal, Quebec, QC, Canada

Conflicts of interest: none reported

\section{CORRESPONDING AUTHOR}

Michèle Aubin, MD, PhD, CCFP, FCFP 2690, Chemin des Quatre-Bourgeois Quebec, QC G1V 0B7, Canada

michele.aubin@mfa.ulaval.ca

\begin{abstract}
PURPOSE There has been little research describing the involvement of family physicians in the follow-up of patients with cancer, especially during the primary treatment phase. We undertook a prospective longitudinal study of patients with lung cancer to assess their family physician's involvement in their follow-up at the different phases of cancer.
\end{abstract}

METHODS In 5 hospitals in the province of Quebec, Canada, patients with a recent diagnosis of lung cancer were surveyed every 3 to 6 months, whether they had metastasis or not, for a maximum of 18 months, to assess aspects of their family physician's involvement in cancer care.

RESULTS Of the 395 participating patients, 92\% had a regular family physician but only $60 \%$ had been referred to a specialist by him/her or a colleague for the diagnosis of their lung cancer. A majority of patients identified the oncology team or oncologists as mainly responsible for their cancer care throughout their cancer journey, except at the advanced phase, where a majority attributed this role to their family physician. At baseline, only $16 \%$ of patients perceived a shared care pattern between their family physician and oncologists, but this proportion increased with cancer progression. Most patients would have liked their family physician to be more involved in all aspects of cancer care.

CONCLUSIONS Although patients perceive that the oncology team is the main party responsible for the follow-up of their lung cancer, they also wish their family physicians to be involved. Better communication and collaboration between family physicians and the oncology team are needed to facilitate shared care in cancer follow-up.

Ann Fam Med 2010;8:526-532. doi:10.1370/afm.1171.

\section{INTRODUCTION}

$\mathrm{M}$ any authors have recognized the lack of continuity in cancer care. ${ }^{1-9}$ Patients with cancer often need to consult many health professionals from multiple settings, leading to fragmented care. At the treatment phase, family physicians may lose track of their patients with cancer, who are usually followed by oncology teams. It may be difficult for family physicians to take over their patients' follow-up at the end of treatments if they have not seen them for a long time..$^{10-16}$

Many health authorities promote collaboration of oncology teams with family physicians to keep them in the loop at all phases of cancer., ${ }^{97-19}$ Little is known on actual family physicians' practices in cancer care, however. Norman et $\mathrm{al}^{12}$ have described 3 patterns of care with increasing levels of family physician involvement: (1) sequential, with virtually no family physician involvement and patients receiving most of their care from the oncology team, (2) parallel, with the family physician still involved but mainly for noncancer problems, and (3) shared, with involvement of both 
the family physician and the oncology team in cancer care. Information on family physician patterns of care throughout the cancer care trajectory is scarce. This study aimed to describe the actual and expected role of family physicians at the different phases of cancer, among a cohort of patients with lung cancer.

\section{METHODS}

\section{Study Design and Patient Selection}

We conducted a prospective longitudinal descriptive study between May 2005 and July 2008 among patients with lung cancer from 5 hospitals in the Canadian province of Quebec. Patients were eligible if they had received a diagnosis of any type of lung cancer, regardless of stage and treatment. We chose this specific cancer because of its high prevalence in men and women, its variable evolution depending on the cellular type and staging at diagnosis, and its diverse treatments. Given these attributes, lung cancer provides the opportunity to document, from the patient's perspective, the change in their family physician's involvement when they move from one cancer phase to another, while following them over a certain period of time.

Eligible patients were informed of the study by the oncology team. Those who agreed to be contacted by the research team were invited to participate and signed an informed consent form. We kept basic information on nonparticipants to compare them with participants. The study was approved by the Research Ethics Committee of Laval University and of all study hospitals.

\section{Data Collection and Study Instruments}

At baseline, patients participated in an interview lasting approximately 45 minutes, either at the oncology clinic or at their home, depending on their preference. They completed questionnaires regarding their social and demographic characteristics; lung cancer history; functional status according to the Eastern Cooperative Oncology Group (ECOG) Performance Status Scale $(0=$ normal activity $1=$ symptoms but ambulatory; $2=$ in bed $<50 \%$ of time; $3=$ in bed $\geq 50 \%$ of time; $4=100 \%$ bedridden $)^{20-22}$; number of visits to the family physician in the prior year, family physician's, specialist's, and oncology team's responsibility for cancer care; family physician's involvement in their care; perceived family physician's actual and expected roles in various aspects of care (coordination, emotional support, information transmission, symptom relief); and the family physician pattern of care (classified according to the previously mentioned categories of Norman et $\left.\mathrm{al}^{12}\right)$. We adapted the questionnaire on family physicians' involvement from the validated primary care assessment tools of Safran et $\mathrm{al}^{23}$ and Starfield et al, ${ }_{1}{ }^{24}$ and used 4 -point Likert scales ( $1=$ not involved $; 2=\mathrm{a}$ little involved $3=$ involved $_{i} 4=$ very involved) that we collapsed into dichotomous categories (not involved vs involved). We performed a test-retest analysis of this instrument on 20 patients, and concordance testing showed no statistically significant difference between the 2 sets of responses for all variables $(P=.31$ to .99$)$. We reviewed patients' medical records to complete information related to lung cancer, treatment received, and services used.

Patients were followed up for a maximum of 18 months. To take into account variability in patients' survival, we reassessed those with metastasis at 3 -month intervals (maximum of 7 interviews) and those without metastasis at 6-month intervals (maximum of 4 interviews). Subsequent interviews lasted 20 to 30 minutes and took place at the oncology clinic, at home, or by telephone, depending on patients' preference. Each time, patients completed the same questionnaires on the number of visits to their family physician since the last interview, actual and expected family physician role in the same aspects of care, and the family physician pattern of care.

We reviewed their medical records each time to determine if metastasis had developed and to ascertain the cancer phase: primary treatment, stability (primary treatment completed and no sign of cancer progression or new metastasis), progression/relapse, or advanced/ terminal. Determination of all phases of cancer was based on medical information from the records, except for the advanced/terminal phase, which was defined as having a score of 3 or 4 on the ECOG scale. We used this approach to avoid misclassification of patients, considering the lack of consensus in the literature on defining this cancer phase from clinical predictors.

\section{Analyses}

We conducted statistical tests on means ( $t$ tests) and proportions ( $\chi^{2}$ tests) to compare participants with nonparticipants on their personal and medical characteristics. Patients' perceptions regarding their family physician's role and pattern of care are presented for each cancer phase. When patients were questioned more than once per phase (ie, if they had an extended period of treatment or there was no progression of cancer over time), a single response per patient per phase was used in the analyses.

For continuous variables, we calculated a mean score from all responses provided by a patient per phase, for each variable, and used this score in analyses. For categorical variables (eg, family physician pattern of care for which the 4 categories - no family physician, sequential, parallel, and shared care-represent an 
increasing level of family physician involvement), we conducted analyses alternatively using either the highest or the lowest score as the sole response per patient per phase. Since we found the results to be equivalent using either of those scores, we arbitrarily decided to present results obtained with the highest score. Notably, in most of these cases, patients questioned repeatedly in a cancer phase reported the same pattern of family physician involvement over time.

We used the Cochran-Mantel-Haenszel test to assess the variation, with the cancer phases, of patients' perceptions regarding their family physician's involvement in cancer care and the family physician pattern of care. Analyses of variance were performed to compare, at each phase, the mean number of visits to the family physician according to pattern of care. An $\alpha$ level of .05 was used as the significance threshold. All statistical analyses were performed using SAS software, version 9.1 (SAS Institute Inc, Cary, North Carolina).

\section{RESULTS}

\section{Patient Disposition and Characteristics}

Of the 695 eligible patients with lung cancer, 395 were recruited for a participation rate of $56.8 \%$. Figure 1 shows patients' participation at each cancer phase. Over the 18-month follow-up, individual patients' courses varied considerably; in fact, we found 15 scenarios of evolution from one phase to another. For example, $52(13.2 \%)$ of the patients continued receiving treatment during the whole study, 192 (48.6\%) remained in the stability phase throughout the followup, and $20(5.1 \%)$ went directly from diagnosis to the progression/relapse or advanced/terminal phases.

Overall, 148 (37.5\%) of the patients died during the study, and 44 (11.1\%) withdrew, mainly because their condition was worsening and they were overwhelmed after receiving the bad news. Also, because of the slow recruitment pace, we extended the recruitment period 6 months longer than originally planned, but the last 95 recruited patients were followed up for only 12 months.

There was no difference according to type of lung cancer between participants and nonparticipants $(P=.50)$. More women than men declined the invitation to participate $(P=.05)$. In addition, participants were slightly younger on average than nonparticipants (63.4 vs 65.5 years $i=.02$ ).

Patients' personal and medical characteristics at baseline are presented in Table 1 . Women were significantly younger than men (61.7 vs 64.7 years; $P=.002$ ) and more frequently lived alone (30.6\% vs $19.9 \%$; $P=.01$ ). Most patients had been aware of their diagnosis for almost 3 months on average. A large proportion of patients $(63.4 \%)$ had positive lymph nodes at diagnosis, and a cumulative $42 \%$ had metastases at some point between diagnosis and the end of the 18 -month follow-up. Almost all patients (92.9\%) were offered a treatment. At baseline, nearly one-third (30.6\%) of patients had been hospitalized at least once in relation to their lung cancer, excluding the 75 patients who were hospitalized for a lung surgery. Only 16.7\% of patients had visited the emergency department for reasons related to their lung cancer, and the majority of patients (77\%) reported being assisted in their care trajectory by a nurse navigator.

\section{Figure 1. Patient participation in the study.}

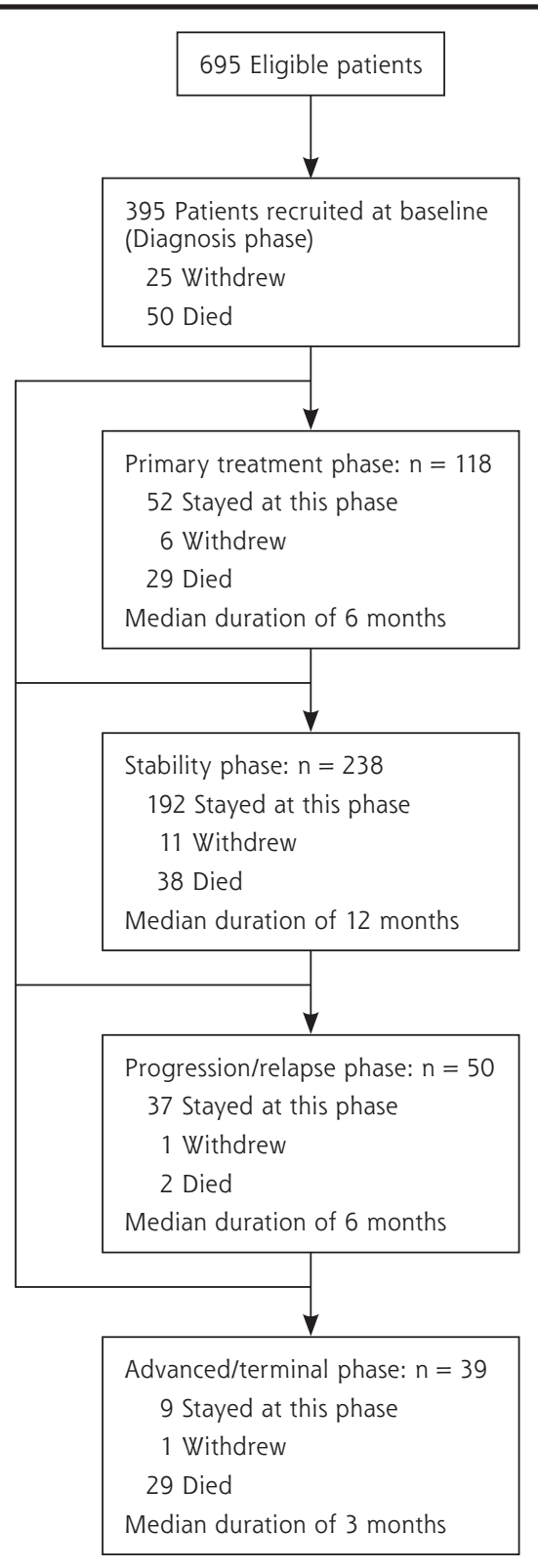




\section{Involvement of Family Physicians in Patients' Cancer Care}

A total of 364 patients (92.1\%) reported having a regular family physician. Among the 31 patients who did not have one, the majority, 19 (61.3\%), wanted to find one, but 12 believed that they should be followed by specialists. Approximately two-thirds of patients had been followed by the same family physician for more than 5 years and, on average, they had consulted him/ her 4 times in the prior year $(4.0 \pm 4.5$; range $0-52)$. Overall, many patients were unaware of their family physician's practice regarding home care (48.4\%) and after-hours care (20.6\%).

Approximately $60 \%$ of patients were referred by

Table 1. Patient Characteristics at Baseline $(\mathbf{N}=395)$

\begin{tabular}{|c|c|}
\hline Characteristic & $\begin{array}{l}\text { No. }(\%) \text { or Mean } \pm \text { SD } \\
\text { (Range) [Median] }\end{array}$ \\
\hline \multicolumn{2}{|l|}{ Sex } \\
\hline Female & $170(43.0)$ \\
\hline Male & $225(57.0)$ \\
\hline \multicolumn{2}{|l|}{ Functional status } \\
\hline Normal activity & $178(45.1)$ \\
\hline Symptoms but ambulatory & $150(37.9)$ \\
\hline $\begin{array}{l}\text { Confined to bed or chair } \\
<50 \% \text { of waking hours }\end{array}$ & $44(11.1)$ \\
\hline $\begin{array}{l}\text { Confined to bed or chair } \\
\geq 50 \% \text { of waking hours }\end{array}$ & $20(5.1)$ \\
\hline $\begin{array}{l}\text { Completely disabled- } \\
\text { 100\% bedridden }\end{array}$ & $3(0.8)$ \\
\hline \multicolumn{2}{|l|}{ Type of lung cancer } \\
\hline Squamous cell carcinoma & $77(19.5)$ \\
\hline Adenomatous carcinoma & $164(41.5)$ \\
\hline Other non-small cell carcinoma & $67(17.0)$ \\
\hline Small cell carcinoma & $58(14.7)$ \\
\hline Unknown & $29(7.3)$ \\
\hline \multicolumn{2}{|l|}{ Treatment } \\
\hline $\begin{array}{l}\text { Surgery with/without chemo- } \\
\text { therapy/radiation therapy }\end{array}$ & $113(28.6)$ \\
\hline $\begin{array}{l}\text { Chemotherapy and/or radiation } \\
\text { therapy }\end{array}$ & $254(64.3)$ \\
\hline No treatment & $28(7.1)$ \\
\hline \multicolumn{2}{|l|}{ Metastases } \\
\hline Present at baseline & $128(32.4)$ \\
\hline Found during follow-up & $37(9.4)$ \\
\hline None & $230(58.2)$ \\
\hline \multicolumn{2}{|l|}{ Cancer stage } \\
\hline Stage I & $56(14.2)$ \\
\hline Stage II & $33(8.3)$ \\
\hline Stage III & $119(30.1)$ \\
\hline Stage IV & $133(33.7)$ \\
\hline Not confirmed & $54(13.7)$ \\
\hline Age, years & $63.4 \pm 9.5(31-88)[64]$ \\
\hline Education, years & $10.9 \pm 3.9(2-24)[11]$ \\
\hline \multicolumn{2}{|l|}{ Intervals in care } \\
\hline Investigation to diagnosis, weeks & $5.6 \pm 8.0(0-78)[3]$ \\
\hline Diagnosis to first treatment, days & $29.0 \pm 26.6(0-140)[21]$ \\
\hline
\end{tabular}

their family physician or a colleague from the same clinic to confirm the diagnosis of lung cancer; the remaining $40 \%$ were referred either by a physician from the emergency department (18\%) or by a specialist (22\%). In most cases $(80.3 \%)$, the family physician assisted patients in making the appointment with the specialist. Among patients referred by other physicians, the large majority $(83.1 \%)$ reported that their family physician was informed of their diagnosis. Most patients reported being satisfied with the time their family physician gave for discussion (93\%) and with his or her patience in responding to questions (93\%), ability to make them at ease $(96 \%)$, and ability to reassure them $(88 \%)$.

A large proportion of patients continued to see their family physician throughout their cancer journey, but predominantly after the end of treatment when their condition was stable $(88 \%)(P<.001)$ (Table 2$)$. At all phases of cancer, a majority of patients reported that they discussed with their family physician their visits to the oncology team, but no more than half of

\section{Table 2. Extent of Family Physician Involvement by Cancer Phase}

\begin{tabular}{|c|c|c|}
\hline Extent of Involvement & $\begin{array}{l}\mathrm{N} \text { (\% of } \\
\text { Patients) }\end{array}$ & $P$ Value $^{a}$ \\
\hline \multicolumn{3}{|l|}{ Contact with family physician } \\
\hline Diagnosis & $364(58.8)$ & \multirow[t]{5}{*}{$<.001$} \\
\hline Primary treatment & $108(60.2)$ & \\
\hline Stability & $228(88.2)$ & \\
\hline Progression/relapse & $48(75.0)$ & \\
\hline Advanced/terminal & $37(67.6)$ & \\
\hline \multicolumn{3}{|c|}{$\begin{array}{l}\text { If contact with family physician, dis- } \\
\text { cussion about visits to oncologist }\end{array}$} \\
\hline Diagnosis & $214(72.9)$ & \multirow[t]{5}{*}{.09} \\
\hline Primary treatment & $65(77.8)$ & \\
\hline Stability & $197(79.7)$ & \\
\hline Progression/relapse & $36(91.7)$ & \\
\hline Advanced/terminal & $22(83.3)$ & \\
\hline \multicolumn{3}{|c|}{$\begin{array}{l}\text { Questions to ask of family physician } \\
\text { in relation to cancer }\end{array}$} \\
\hline Diagnosis & $214(32.7)$ & \multirow[t]{5}{*}{$<.001$} \\
\hline Primary treatment & $65(43.1)$ & \\
\hline Stability & $201(44.3)$ & \\
\hline Progression/relapse & $36(50.0)$ & \\
\hline Advanced/terminal & $25(64.0)$ & \\
\hline \multicolumn{3}{|c|}{$\begin{array}{l}\text { Family physician involvement in } \\
\text { treatment decisions }^{\mathrm{b}}\end{array}$} \\
\hline Diagnosisc $^{c}$ & - & \multirow[t]{5}{*}{$<.001$} \\
\hline Primary treatment & $53(15.1)$ & \\
\hline Stability & $107(16.8)$ & \\
\hline Progression/relapse & $34(20.6)$ & \\
\hline Advanced/terminal & $13(53.9)$ & \\
\hline \multicolumn{3}{|c|}{$\begin{array}{l}\text { a From the Cochran-Mantel-Haenszel test; compares, across cancer phases, the } \\
\text { proportion of patients who reported each extent of family physician involvement. } \\
\text { b Only for patients who had treatment. } \\
\text { ' This question was not asked at the diagnosis phase; often, treatment had } \\
\text { already begun at the baseline interview. }\end{array}$} \\
\hline
\end{tabular}


patients had additional questions to ask to their family physician in relation to their lung cancer, except at the advanced/terminal phase, where this situation was more common $(64 \%)(P<.001)$. Similarly, at most cancer phases except the advanced/terminal one, few patients reported that their family physician was involved in decisions regarding cancer treatment.

\section{Table 3. Family Physician Involvement in Various} Aspects of Care by Cancer Phase

\begin{tabular}{|c|c|c|c|}
\hline Aspect of Care & $\begin{array}{c}\text { Actual } \\
\text { Involvement } \\
\mathbf{N} \text { ( } \% \text { of } \\
\text { Patients) }\end{array}$ & $\begin{array}{c}\text { Expected } \\
\text { Involvement } \\
\mathbf{N} \text { ( } \% \text { of } \\
\text { Patients) }\end{array}$ & $\begin{array}{c}P \\
\text { Value }^{a}\end{array}$ \\
\hline \multicolumn{4}{|l|}{ Coordination of care } \\
\hline Diagnosis & $357(41.2)$ & 362 (83.4) & $<.001$ \\
\hline Primary treatment & $102(24.5)$ & $107(83.2)$ & $<.001$ \\
\hline Stability & $227(31.3)$ & $228(85.1)$ & $<.001$ \\
\hline $\begin{array}{l}\text { Progression/ } \\
\text { relapse }\end{array}$ & $46(37.0)$ & $48(75.0)$ & $<.001$ \\
\hline Advanced/terminal & $37(46.0)$ & $37(86.5)$ & $<.001$ \\
\hline \multicolumn{4}{|l|}{ Emotional support } \\
\hline Diagnosis & $351(36.8)$ & $362(83.4)$ & $<.001$ \\
\hline Primary treatment & $104(44.2)$ & $107(86.9)$ & $<.001$ \\
\hline Stability & $227(54.6)$ & $228(88.2)$ & $<.001$ \\
\hline Progression/relapse & $46(60.9)$ & $48(87.5)$ & .002 \\
\hline Advanced/terminal & $37(51.4)$ & $37(81.1)$ & .007 \\
\hline \multicolumn{4}{|l|}{$\begin{array}{l}\text { Transmission of } \\
\text { information }\end{array}$} \\
\hline Diagnosis & $352(17.3)$ & $362(62.0)$ & $<.001$ \\
\hline Primary treatment & $103(18.4)$ & 107 (59.8) & $<.001$ \\
\hline Stability & $227(29.1)$ & $228(72.4)$ & $<.001$ \\
\hline $\begin{array}{l}\text { Progression/ } \\
\text { relapse }\end{array}$ & $46(34.8)$ & $48(58.3)$ & .01 \\
\hline Advanced/terminal & $37(37.8)$ & $37(73.0)$ & .002 \\
\hline \multicolumn{4}{|l|}{ Symptom relief } \\
\hline Diagnosis & $332(13.0)$ & $361(62.3)$ & $<.001$ \\
\hline Primary treatment & $100(19.0)$ & $107(74.8)$ & $<.001$ \\
\hline Stability & $225(30.2)$ & $228(79.8)$ & $<.001$ \\
\hline Progression/relapse & $46(30.4)$ & $48(72.9)$ & $<.001$ \\
\hline Advanced/terminal & $37(43.2)$ & 37 (78.4) & .002 \\
\hline
\end{tabular}

a From the $\chi^{2}$ test; compares, at each cancer phase, the actual vs expected proportions for family physician involvement in specific aspects of cancer care, as reported by patients.

\section{Actual and Expected Family Physician Involvement in Cancer Care}

Although family physicians contributed modestly to cancer care follow-up, most patients were satisfied in general with their family physician's involvement. Nevertheless, when questioned on specific aspects of cancer care, there was a significant gap between patients' perception of the actual involvement of their family physician and their expectations regarding his/ her contribution in coordination of care, emotional support, information transmission, and symptom relief (Table 3). At all phases of cancer, most patients would have liked their family physician to be more involved than he/she actually was in all these aspects of care $(P<.05)$.

Table 4 shows patients' perception of their family physician's pattern of care at the different phases of cancer. Although the proportion of patients without a regular physician did not vary significantly with the evolution of cancer, the 3 other patterns of care differed from diagnosis to the advanced/terminal phase. Parallel care was the most frequent pattern reported at all phases of cancer, except at the advanced/terminal phase, where shared care was identified more often.

At diagnosis, patients reported a mean number of visits to their family physician in the prior year that was significantly different according to their perceived family physician's pattern of care $(P<.001)$. In particular, there was increasing family physician involvement from the sequential pattern of care $(2.4 \pm 2.5$ visits $)$ to the parallel pattern of care $(3.9 \pm 3.6)$, and also from the parallel to the shared care pattern $(5.6 \pm 7.3)$. The same difference was consistently seen between the patterns of care at all other cancer phases (Table 5).

Finally, when asked independently for each type of health care professional, more than $90 \%$ of patients considered oncologists to be the main professionals responsible for their cancer care at all phases but one. The exception was the advanced phase, where more than $70 \%$ patients gave this responsibility to their family physician.

Table 4. Family Physician Pattern of Care by Cancer Phase

\begin{tabular}{|c|c|c|c|c|c|c|}
\hline \multirow[b]{2}{*}{ Pattern of Care } & \multicolumn{5}{|c|}{ Cancer Phase } & \multirow[b]{2}{*}{ P Value } \\
\hline & $\begin{array}{l}\text { Diagnosis } \\
(\mathrm{N}=395)\end{array}$ & $\begin{array}{l}\text { Primary Treatment } \\
(\mathrm{n}=118)\end{array}$ & $\begin{array}{l}\text { Stability } \\
(n=238)\end{array}$ & $\begin{array}{l}\text { Progression/Relapse } \\
(n=50)\end{array}$ & $\begin{array}{l}\text { Advanced/Terminal } \\
(\mathrm{n}=39)\end{array}$ & \\
\hline No family physician & 7.8 & 8.5 & 4.2 & 4.0 & 5.1 & .31 \\
\hline Sequential & 11.6 & 12.7 & 3.8 & 2.0 & 18.0 & $<.001$ \\
\hline Parallel & 64.6 & 54.2 & 55.9 & 62.0 & 23.1 & $<.001$ \\
\hline Shared & 16.0 & 24.6 & 36.1 & 32.0 & 53.8 & $<.001$ \\
\hline
\end{tabular}




\section{Table 5. Patient Visits to Their Family Physician by Cancer Phase} and Pattern of Care ${ }^{a}$

\begin{tabular}{lccccc}
\hline & \multicolumn{4}{c}{ Pattern of Care } & \\
\cline { 2 - 5 } Cancer Phase & $\begin{array}{c}\text { No Family } \\
\text { Physician }\end{array}$ & Sequential & Parallel & Shared Care & Value $^{\text {b }}$ \\
\hline Primary treatment & - & 0.00 & $0.89 \pm 1.38$ & $2.25 \pm 1.73$ & $<.001$ \\
Stability & - & 0.00 & $1.28 \pm 1.26$ & $2.54 \pm 2.52$ & $<.001$ \\
Progression/relapse & - & $0.72 \pm 0.00$ & $1.33 \pm 1.48$ & $3.21 \pm 3.27$ & .02 \\
Advanced/terminal & - & $0.67 \pm 0.82$ & $1.20 \pm 1.81$ & $2.37 \pm 1.30$ & .02 \\
\hline
\end{tabular}

Note: Values are mean \pm standard deviation number of visits.

a Values should not be compared from one cancer phase to another since duration of each phase was not equivalent.

b From analysis of variance; compares, at each cancer phase, the mean number of visits to the family physician according to family physician patterns of care.

\section{DISCUSSION}

This study provides new knowledge regarding family physicians' actual and expected involvement in cancer care, as no other longitudinal study has looked at these physicians' role throughout the cancer care trajectory, to the best of our knowledge. Recently, Cheung et $\mathrm{al}^{25}$ have documented patients' expectations regarding some aspects of cancer follow-up specifically for survivorship care. This latter study complements our results by also providing a comparison of patients' expectations to the ones of family physicians and oncologists. But their study was cross-sectional and limited to cancer survivorship care, compared with ours, which addressed the evolution of patients' expectations from diagnosis to the advanced/terminal phase of cancer.

In our cohort, most patients reported having a regular family physician, a finding that is concordant with findings from other studies with patients of similar age. ${ }^{16,26}$ Throughout the cancer care trajectory, less than $50 \%$ of patients reported a high degree of family physician involvement in most aspects of cancer care. These physicians were least involved during the primary treatment phase of cancer, as reported by patients. This study thus confirms that family physicians are largely cut off from cancer care during the treatment phase, as has been found in other studies. ${ }^{10,16}$

From diagnosis to the progression phase, the pattern of care most frequently reported was the parallel one, which corresponds to some family physician involvement in follow-up, but mainly for noncancer health problems. Shared care between family physicians and the oncology team was mentioned increasingly as the cancer progressed, and became the most frequent pattern of care at the advanced/terminal phase. These results are consistent with findings of Sisler et al, ${ }^{16}$ but they provide additional information by documenting the change in pattern of care during the cancer care trajectory. They seem to reflect patients' preference for a shift in care toward specialists after the diagnosis of cancer until they reach the advanced phase of their disease, at which point a substantial proportion turn back to their family physician. In that sense, the parallel pattern of care may be perceived by patients as providing better-defined roles for both family physicians and oncologists, compared with a shared pattern of care that requires good communication between physicians to determine how best to interface with each other in delivering care to patients. These findings may also explain why a majority of patients were satisfied with their family physician's overall level of involvement, even though few of them reported a high level of family physician involvement in their cancer care. Nevertheless, as Cheung et $\mathrm{al}^{25}$ concluded, the respective roles expected of family physicians and oncologists need to be clarified in order to provide continuous and integrated cancer care.

Despite patients' high degree of satisfaction with their family physician's level of involvement overall, there was a significant gap, at all phases of cancer, between their perception of their family physician's actual follow-up and what they expected from them in specific aspects of cancer care. These contrasting results emphasize the importance of assessing specific domains of satisfaction. The gap found between patients' experiences and expectations mirrors findings of Miedema et al, ${ }^{27}$ which showed that $80 \%$ of surveyed cancer patients wanted counseling from their family physician about the emotional issues of cancer, but only $20 \%$ received it.

There are some limitations to this study. First, the rather low participation rate combined with the high dropout rate may raise some concerns. But these rates compare well with those of other studies conducted with such a vulnerable population. ${ }^{16,25,28}$ Moreover, the withdrawal rate was quite low in this cohort, the main reasons for dropping out being death or cancer recurrence associated with poor functional status, which were inevitable in this population. Second, because the study was limited to patients with lung cancer, it is uncertain if results may be generalized to patients with other types of cancer. Since the cohort included patients varied in age, sex, stage at diagnosis, and treatments received, however, it gives insights into patients' preferences on cancer follow-up care that may also apply to other cancers. Third, the classification of family physician patterns of care relied on patients' perception, which may be considered imprecise. Nevertheless, there was a significant difference, at baseline and for 
each cancer phase, in the mean number of patient visits to their family physician according to this pattern of care, supporting the validity of this classification originally described by Norman et al. ${ }^{12}$ Finally, our findings are based on self-reported data, and they must be interpreted with caution given the small number of participants in some phases of cancer, particularly at the progression/relapse and advanced/terminal phases.

Despite these limitations, this study provides valuable information on how patients with lung cancer experience family physicians' contribution to their care and what they expect from them, throughout their cancer journey. As highlighted by other authors, ${ }_{1}^{10,16,29-31}$ this research reinforces the importance of good communication and collaboration between family physicians and the oncology team in order to keep the former involved at all phases of cancer and to promote shared care in cancer follow-up. Future research should focus on developing and evaluating innovative strategies to increase interprofessional collaboration to ultimately improve continuity of care for patients with cancer.

\section{To read or post commentaries in response to this article, see it} online at http://www.annfammed.org/cgi/content/full/8/6/526.

Key words: Cancer care; family physicians; primary care; patient care; patient care team; multidisciplinary communication; collaboration; continuity of care; cancer follow-up

Submitted December 14, 2009; submitted, revised, April 8, 2010; accepted May 18, 2010.

Funding support: This study was supported by an operating grant of the Canadian Institutes of Health Research (CIHR), grant MOP-68834.

Acknowledgments: The authors thank Mr Serge Simard, biostatistician, for his advice on data analyses, and Mrs Lucie Misson and Danielle Marleau for their role in patient interviewing and data collection.

\section{References}

1. Dudgeon D, Vaitonis V, Seow $H$, King S, Angus $H$, Sawka C. Ontario, Canada: using networks to integrate palliative care province-wide. J Pain Symptom Manage. 2007;33(5):640-644.

2. Dumont I, Dumont S, Turgeon J. Continuity of care for advanced cancer patients. J Palliat Care. 2005;21(1):49-56.

3. Grunfeld E. Looking beyond survival: how are we looking at survivorship? J Clin Oncol. 2006;24(32):5166-5169.

4. Earle CC. Failing to plan is planning to fail: improving the quality of care with survivorship care plans. J Clin Oncol. 2006;24(32):5112-5116.

5. Smith SD, Nicol KM, Devereux J, Cornbleet MA. Encounters with doctors: quantity and quality. Palliat Med. 1999;13(3):217-223.

6. Gysels M, Richardson A, Higginson IJ. Does the patient-held record improve continuity and related outcomes in cancer care: a systematic review. Health Expect. 2007;10(1):75-91.

7. Haggerty JL, Reid RJ, Freeman GK, Starfield BH, Adair CE, McKendry R. Continuity of care: a multidisciplinary review. BMJ. 2003;327(7425):1219-1221.

8. Hewitt M, Greenfield S, Stovall E, eds. Institute of Medicine, National Research Council. From Cancer Patient to Cancer Survivor: Lost in Transition. Washington, DC: The National Academies Press; 2006.
9. Adler NE, Page AEK, eds. Institute of Medicine, National Research Council. Cancer Care for the Whole Patient: Meeting Psychosocial Health Needs. Washington, DC: The National Academies Press; 2008.

10. McWhinney IR, Hoddinott SN, Bass MJ, Gay K, Shearer R. Role of the family physician in the care of cancer patients. Can Fam Physician. 1990;36:2183-2186.

11. Wood ML. Communication between cancer specialists and family doctors. Can Fam Physician. 1993;39:49-57.

12. Norman A, Sisler J, Hack T, Harlos M. Family physicians and cancer care. Palliative care patients' perspectives. Can Fam Physician. 2001;47:2009-2012, 2015-2016.

13. Worster A, Bass MJ, Wood ML. Willingness to follow breast cancer: survey of family physicians. Can Fam Physician. 1996;42:263-268.

14. Williams PT. The role of family physicians in the management of cancer patients. J Cancer Educ. 1994;9(2):67-72.

15. Anvik T, Holtedahl KA, Mikalsen H. "When patients have cancer, they stop seeing me"-the role of the general practitioner in early follow-up of patients with cancer-a qualitative study. BMC Fam Pract. 2006;7:19.

16. Sisler JJ, Belle Brown J, Stewart M. Family physicians' role in cancer care. Can Fam Physician. 2004;50:889-896.

17. Ministère de la Santé et des Services sociaux du Québec. Programme Québécois de Lutte Contre le Cancer: Pour Lutter Efficacement Contre le Cancer, Formons Equipe. Quebec, Canada: Gouvernement du Québec; 1997. http://publications.msss.gouv.qc.ca/acrobat/f /documentation/1997/97-729-5.pdf. Accessed April 15, 2010.

18. Ministère de la Santé et des Services sociaux du Québec. Orientations Prioritaires 2007-2012 du Programme Québécois de Lutte Contre le Cancer. Quebec, Canada: Gouvernement du Québec; 2007. http:// publications.msss.gouv.qc.ca/acrobat/f/documentation/2007/07902-03.pdf. Accessed April 15, 2010.

19. Cancer Australia. CanNET: Cancer service networks national demonstration program. Canberra, Australia: Cancer Australia; 2008. http://www.canceraustralia.gov.au/cannet/primary-care-involvement /primary-care-involvement. Accessed April 15, 2010.

20. Bowling A. Measuring Disease: A Review of Disease-Specific Quality of Life Measurement Scales. Buckingham, England, and Philadelphia, PA: Open University Press; 1995.

21. Schag CC, Heinrich RL, Ganz PA. Karnofsky performance status revisited: reliability, validity, and guidelines. J Clin Oncol. 1984;2(3):187-193.

22. Taylor EA, Olver IN, Sivanthan T, Chi M, Purnell C. Observer Error in Grading Performance Status in Cancer Patients: Supportive Care in Cancer. Berlin and Heidelberg, Germany: Springer-Verlag; 1999.

23. Safran DG, Kosinski M, Tarlov AR, et al. The Primary Care Assessment Survey: tests of data quality and measurement performance. Med Care. 1998;36(5):728-739.

24. Starfield B, Leiyu S, Xu J. Validating the adult primary care assessment tool. J Fam Pract. 2001;50(2):161-175.

25. Cheung WY, Neville BA, Cameron DB, Cook EF, Earle CC. Comparisons of patient and physician expectations for cancer survivorship care. J Clin Oncol. 2009;27(15):2489-2495.

26. Statistics Canada. Canadian Community Health Survey 2007. http:// www.statcan.ca/Daily/English/080618/d080618a.htm. Accessed June 18, 2008.

27. Miedema B, MacDonald I, Tatemichi S. Cancer follow-up care. Patients' perspectives. Can Fam Physician. 2003;49:890-895.

28. Aubin $M$, Vézina $L$, Parent $R$, et al. Impact of an educational program on pain management in patients with cancer living at home. Oncol Nurs Forum. 2006;33(6):1183-1188.

29. Bulsara C, Ward AM, Joske D. Patient perceptions of the GP role in cancer management. Aust Fam Physician. 2005;34(4):299-300, 302.

30. Smith GF, Toonen TR. Primary care of the patient with cancer. Am Fam Physician. 2007;75(8):1207-1214.

31. Johansson B, Berglund G, Hoffman K, Glimelius B, Sjöden PO. The role of the general practitioner in cancer care and the effect of an extended information routine. Scand J Prim Health Care. 2000;18(3): 143-148. 